\title{
Biodistribution and Dosimetry of Indigenously Produced 131I-Rituximab in B-Cell Lymphoma: Pilot Study Estimating Patient-Specific Dose Comparing 2 Different Dosimetric Methods
}

\author{
Aadil Adnan ${ }^{1,2}$, Kamal Deep ${ }^{2,3}$, Mythilli Kameswarann ${ }^{2,4}$, Dilip Nikam ${ }^{5}$, Chandrakala Shanmukaih ${ }^{6}$, Ashutosh Dash ${ }^{2,4}$, \\ Sharmila Banerjee ${ }^{1,2}$, and Sandip Basu ${ }^{1,2}$ \\ ${ }^{1}$ Radiation Medicine Centre, Bhabha Atomic Research Centre, Tata Memorial Centre Annexe, Mumbai, India; ${ }^{2}$ Homi Bhabha \\ National Institute, Mumbai, India; ${ }^{3}$ Radiation Safety Systems Division, Cama and Albless Hospital, Mumbai, India; \\ ${ }^{4}$ Radiopharmaceutical Division, Cama and Albless Hospital, Mumbai, India; ${ }^{5}$ Department of Radiotherapy and Oncology, Cama \\ and Albless Hospital, Mumbai, India; and ${ }^{6}$ Department of Hematology, King Edward Memorial Hospital, Mumbai, India
}

\begin{abstract}
Cost containment through indigenous production of radioimmunotherapy agents for non-Hodgkin lymphoma (NHL) would be a pivotal step toward wider clinical availability, especially in developing countries. We examined the biodistribution and dosimetry of indigenously developed and radiolabeled ${ }^{131}$ I-rituximab, using the monoclonal antibody of chimeric origin, in patients with B-cell lymphoma for potential use in radioimmunotherapy. Methods: This prospective study included 13 patients with Bcell NHL who underwent low-dose diagnostic scanning for dosi-
\end{abstract} metric and biodistribution studies. Soon after rituximab infusion, a diagnostic dose of radioiodinated rituximab was administered. Serial planar whole-body $y$-camera images were taken soon afterward and on days 1, 2, 4, and 6. A source of ${ }^{131}$ I with known activity was used as a reference standard for dosimetry calculations. Results: The patient-specific administered dose that would give a whole-body absorbed radiation dose of 75 cGy, calculated by the MIRD schema, ranged from 3,095.42 to 6,330.33 MBq (83.66-171.09 $\mathrm{mCi})$, with a mean of $3,986.01 \pm$ 863.95 MBq $(107.73 \pm 23.35 \mathrm{mCi})$ and a median of $3,697.41$ $\mathrm{MBq}(99.93 \mathrm{mCi})$. The mean residence time was $69.54 \mathrm{~h}$. Within the first $48 \mathrm{~h}$ at least $50 \%$ of the injected activity was cleared, and by $144 \mathrm{~h}$ at least $80 \%$ was cleared. The patient-specific administered dose that would give a whole-body absorbed radiation dose of 75 cGy, calculated by mean residence time and activity-hours, ranged from $2,654.75$ to $6,210.45 \mathrm{MBq}$ (71.75$167.85 \mathrm{mCi}$ ), with a mean of $3,576.42 \pm 927.59 \mathrm{MBq}(96.66 \pm$ $25.07 \mathrm{mCi}$ ) and a median of $3,421.02 \mathrm{MBq}(92.46 \mathrm{mCi})$. With respect to organ-specific dosimetry, the mean absorbed doses to organs (apart from blood pool [3.77 Gy] and spleen [4.02 Gy]) were 0.97 Gy to the lungs, 0.69 Gy to the liver, and 0.7 Gy to the kidneys. Conclusion: The indigenous product had kinetics similar to commercial radiopharmaceuticals, with the advantage of a lower human antimouse antibody response because of the pharmaceutical's being a chimeric antibody rather than a murine

\footnotetext{
Received Jun. 28, 2018; revision accepted Oct. 2, 2018.

For correspondence or reprints contact: Sandip Basu, Radiation Medicine Centre, Bhabha Atomic Research Centre, Tata Memorial Hospital Annexe, Jerbai Wadia Rd., Parel, Mumbai, Maharashtra, India, 400012.

E-mail: drsanb@yahoo.com

Published online Nov. 9, 2018.

COPYRIGHT (C) 2019 by the Society of Nuclear Medicine and Molecular Imaging.
}

antibody. Hence, clinical administration was safe. In none of the organs did dose-limiting radiation exposure occur at the proposed therapeutic dose.

Key Words: ${ }^{131}$ I-rituximab; B-cell lymphoma; radioimmunotherapy; dosimetry

J Nucl Med Technol 2019; 47:292-299

DOI: 10.2967/jnmt.118.216754

$\mathbf{M}$ alignancy of lymphoid cells ranges from indolent to highly aggressive forms (1). Thomas Hodgkin, for whom Hodgkin lymphoma is named, published the first description of lymphoma in 1832 (2). Lymphoma is one of the most common hematologic malignancies worldwide, with an estimated 74,680 new cases diagnosed in the United States in 2017 and 2018 (3-5). It comprises 3\%-4\% of all malignancies and is ranked as the seventh most common cancer overall $(6,7)$ and the third most common in children (8), and its incidence is higher in developed countries than in developing countries (6). These cancers arise from the immune system at different stages of differentiation, causing a wide range of morphologic, immunologic, and clinical findings ( 1 ). Once the diagnosis is established, there are several treatment options: chemotherapy with cyclophosphamide, doxorubicin, vincristine, and prednisone (most commonly); combination chemotherapy-immunotherapy with rituximab, cyclophosphamide, doxorubicin, vincristine, and prednisone; radiation; and hematopoietic stem cell transplantation. Despite the multitude of chemotherapeutic options available for recurrence, none has had a significant impact on survival, with low cost effectiveness and poor safety profiles $(9,10)$.

More recently, radioimmunotherapy, which uses a monoclonal antibody in addition to a radionuclide to deliver radiation to the sites of disease, has been extensively studied with encouraging results $(9,11)$. Radioimmunotherapy combines 
the benefits of immunotherapy and radioisotopes and has been shown to be effective for non-Hodgkin lymphoma (NHL), both in relapsed or refractory cases and in newly diagnosed cases. Although initial success was found for lowgrade NHL, recent studies have shown promising results in other types of lymphoma, even Mantle cell and aggressive diffuse large cell disease.

Lymphomas are sensitive to radiation, and radioimmunotherapy delivers total-body radiation in a more directed and continuous fashion (12), with more selectivity for tumor tissues than for normal background viscera. The irradiated cells are arrested at the G2 phase of the growth cycle, induces DNA damage with an impaired repair mechanism, and finally culminates in apoptosis. Moreover, the radioisotope exerts a cytotoxic effect over a spheric volume in its immediate vicinity and thereby targets inaccessible and antigen-deficient tumor cells by the crossfire effect $(13,14)$, thus alleviating refractoriness.

Many of the available radioimmunotherapy options use murine monoclonal antibodies and hence are more prone to causing a human antimouse antibody reaction. This problem limits their use in NHL patients, and retreatment is associated with a progressively increasing risk of hypersensitivity reactions. Hence, radioconjugation of the chimeric monoclonal anti-CD20 antibody is an effective strategy to circumvent the development of human antimouse antibody and allow safe retreatment. Radioiodination of rituximab is an easy and safe method and has been done in the nuclear medicine laboratory by the chloramine $\mathrm{T}$ method $(15,16)$.

\section{MATERIALS AND METHODS}

Thirteen patients ( 6 male and 7 female; age range, 30-70 y; median, 61 y) with biopsy-proven B-cell NHL with CD20 positivity on immunohistochemistry were recruited for this prospective dosimetric study (Table 1). To be included, the patients had to be planned to receive rituximab-based chemotherapy in a medical oncology facility, have an absolute neutrophil count of at least $1,500 \times 10^{6} / \mathrm{L}$, a platelet count of at least $100,000 \times 10^{6} / \mathrm{L}$, and a bone marrow biopsy showing at least $15 \%$ normal cellularity and less than $25 \%$ lymphoma cells.

The types of lymphoma included diffuse large cell B-cell lymphoma (39\% of patients, one of whom had the gastric form), follicular lymphoma (30\%), mantle cell lymphoma (15\%), splenic marginal zone lymphoma (8\%), or primary central nervous system lymphoma (8\%). The patient with primary central nervous system lymphoma had undergone surgery for the same. All patients had undergone at least 2 cycles of chemotherapy with rituximab, cyclophosphamide, doxorubicin, vincristine, and prednisone. None of the enrolled patients had thrombocytopenia (hence, dose capping at 65 cGy was not required).

The patients received rituximab-based chemotherapy under medical oncology supervision. Soon afterward (4-6 h), they were administered a small diagnostic dose $(\sim 259-444 \mathrm{MBq}[\sim 7-12$ $\mathrm{mCi}]$ ) of the indigenously produced radioiodinated rituximab by intravenous infusion in $0.9 \%$ normal saline over 15-20 min.

Anterior and posterior serial planar whole-body $\gamma$-camera images were taken soon after the infusion (before and after voiding) and at days 1, 2, 4, and 6. All imaging were performed on a
TABLE 1

Demographic Data

\begin{tabular}{|cc}
\hline \multicolumn{1}{c}{ Parameter } & Data \\
\hline Total patients $(n)$ & 13 \\
\hline Age $(y)$ & \\
Range & $30-70$ \\
\hline Median & 61 \\
Sex $(n)$ & \\
Male & 6 \\
\hline Female & 7 \\
Weight $(k g)$ & \\
Range & $45-87$ \\
Median & 55 \\
\hline Type of NHL $(n)$ & 5 \\
DLBCL & 4 \\
Follicular & 2 \\
Mantle cell & 1 \\
Splenic marginal zone & 1 \\
Primary CNS lymphoma &
\end{tabular}

CNS $=$ central nervous system; DLBCL $=$ diffuse large cell B-cell lymphoma.

Siemens Symbia dual-head camera equipped with 1.0-cm NaI(Tl) crystals and high-energy collimators. A $15 \%$ energy window around $364 \mathrm{keV}$, the dominant $\gamma$-ray energy of ${ }^{131} \mathrm{I}$, was applied. During each whole-body image, a source of ${ }^{131} \mathrm{I}$ with known activity was used as a reference standard for dosimetry calculations.

\section{Image Analysis}

The images were further analyzed using Syngo MI software, version VA60A/VA46A, on a Siemens workstation. All 5 scans were compared, and regions of interest were drawn over the whole body (anterior and posterior) and a ${ }^{131} \mathrm{I}$ source with known activity placed alongside the patient during each scan. From each region of interest, counts were obtained and the geometric mean calculated for the whole body and the ${ }^{131}$ I source. From these counts, we calculated an attenuation factor and, hence, the activity retained in the patient's body.

The administered activity (radiopharmaceutical dose) that would give a whole-body absorbed radiation dose of 75 cGy (17-20) (normal platelet count $\geq 150,000 / \mu \mathrm{L}$ ) and $65 \mathrm{cGy}(17-20)$ (platelet count of $100,000-150,000 / \mu \mathrm{L})$ was calculated by 2 methods.

In the first method, the cumulative-activity method, the timeactivity curve for each patient is constructed from activity retained in the patient's body using Origin Pro 8 SRO software (Origin Lab Corp.). Whole-body cumulative activity is estimated by calculating the area under the curve (from time zero to time when extrapolated graph touches baseline [when percentage injected activity is almost negligible, that is, the body is cleared of activity]), which, when multiplied by the patient-specific $\mathrm{S}$ factor for ${ }^{131} \mathrm{I}$ (calculated from a given value of $9.9 \mathrm{E}-06 \mathrm{cGy} / \mu \mathrm{Ci}-\mathrm{h}$ for a $73.0-\mathrm{kg}$ reference person), gives the mean absorbed radiation dose (cGy). Using the unitary method, the dose that would give a whole-body absorbed radiation dose of $75 \mathrm{cGy}$ (or $65 \mathrm{cGy}$, depending on the platelet count) is calculated: this is the desired dose to administer. The absorbed radiation dose for the whole body is estimated according to the MIRD scheme as follows: mean absorbed radiation dose (cGy) = cumulative activity $\times \mathrm{S}$ factor.

The second method of calculating the administered activity is the residence-time method. Percentage retained activity is plotted 
versus time on semilogarithmic graph paper and used to determine the residence time, which is defined as the time for the semilogarithmic plot to reach 0.37 times the injected activity. Activityhours (mCi-h) was the product of the amount of radioactivity and the residence time. For calculation of patient-specific therapeutic dose, the first step was to divide the activity-hours by the patientspecific residence time. The activity-hours to deliver a 75-cGy total-body dose with ${ }^{131}$ I for a given body mass was determined and used in this method. The therapeutic dose was calculated as previously described (20): therapeutic dose $(\mathrm{mCi})=$ [activityhours $(\mathrm{mCi}-\mathrm{h}) /$ residence time $(\mathrm{h})] \times[$ desired total-body absorbed radiation dose (65 or $75 \mathrm{cGy}) / 75 \mathrm{cGy}]$.

Serial $\gamma$-camera whole-body images were analyzed with respect to time by visual, semiquantitative, and quantitative approaches to determine the pharmacokinetics and clearance pattern. Pixelmatched background-corrected regions of interest were drawn around the major critical organs (heart, lung, liver, spleen, and kidney) on the serial planar images in both anterior and posterior projections. The geometric mean of the anterior and posterior counts was obtained. The organ-specific dosimetry was performed with CT-based organ volume calculations, and the residence time in each organ was calculated. Organ-specific absorbed radiation doses for both the diagnostic and the therapeutic radiopharmaceutical dose (calculated by projecting the diagnostic dose to the therapeutic activity) to these organs were calculated according to the standard MIRD formulation. As per convention, the maximum dose-limiting organ-specific dose to the organs was considered to be $20 \mathrm{~Gy}(2,000 \mathrm{rad})$.

\section{RESULTS}

\section{Whole-Body Clearance Pattern}

The residence time of the indigenous radiopharmaceutical (time required for whole-body activity to drop to $37 \%$ of injected activity, as calculated from a semilogarithmic graph of percentage injected activity vs. time) ranged from 40 to $100 \mathrm{~h}$ (mean, $69.54 \mathrm{~h}$; median, $73 \mathrm{~h}$ ).

Whole-body clearance of the radiopharmaceutical was assessed by the percentage of injected activity remaining in the body as obtained by the counts from the serial $\gamma$-camera images. Two components of clearance were noted: rapid and slow. The rapid component represented exponential clearance and was between 48 and $72 \mathrm{~h}$ in all patients. The slow component, which when extrapolated touched the baseline (representing near-complete to complete clearance of activity from the body), was between 190 and $330 \mathrm{~h}$ (mean total clearance time, $230 \mathrm{~h}$ ). Within the first $48 \mathrm{~h}$ (the second day) at least $50 \%$ of the injected activity was cleared from the body in all the patients, and by $144 \mathrm{~h}$ (the sixth day) at least $80 \%$ was cleared.

The time-activity curves of the patients with the fastest clearance and slowest clearance, hence requiring administration of the minimum and maximum calculated doses (to give a whole-body absorbed radiation dose of $75 \mathrm{cGy}$ ), are shown in Figures 1 and 2. Analyzing both curves, we can see that in the patient requiring the lowest administered dose $(3,095.42 \mathrm{MBq}$ [83.66 $\mathrm{mCi}])$, the rapid component is almost negligible, and about $240 \mathrm{~h}(10 \mathrm{~d})$ is needed for complete clearance of the radiopharmaceutical from the

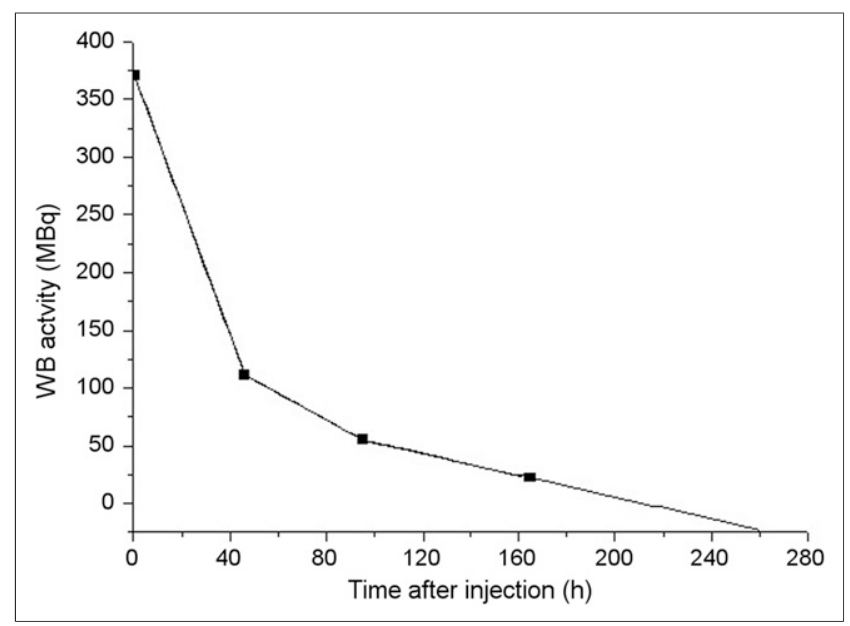

FIGURE 1. Time-activity curve of patient requiring minimum dose. WB $=$ whole body.

body. On the other hand, the patient requiring the maximum dose $(6,330.33 \mathrm{MBq}$ [171.09 $\mathrm{mCi}])$ has a steep, rapid component, with more than $70 \%$ of the injected activity being cleared within the first $48 \mathrm{~h}$. The slow component of the time-activity curve represents clearance of the remaining less than $30 \%$ of the injected activity, and about $210 \mathrm{~h}(8.75 \mathrm{~d})$ is needed for complete clearance of the radiopharmaceutical from the body.

\section{Individual-Organ Clearance Pattern}

Clearance of radiopharmaceutical from the major organs nearly followed the whole-body clearance pattern, that is, initial rapid or exponential clearance followed by prolonged slow clearance.

The radiopharmaceutical showed a prolonged residence in the blood pool (including heart) and in major normal organs (liver, spleen, and kidneys) (Figs. 3-5). The maximum mean absorbed radiation dose per unit of diagnostic

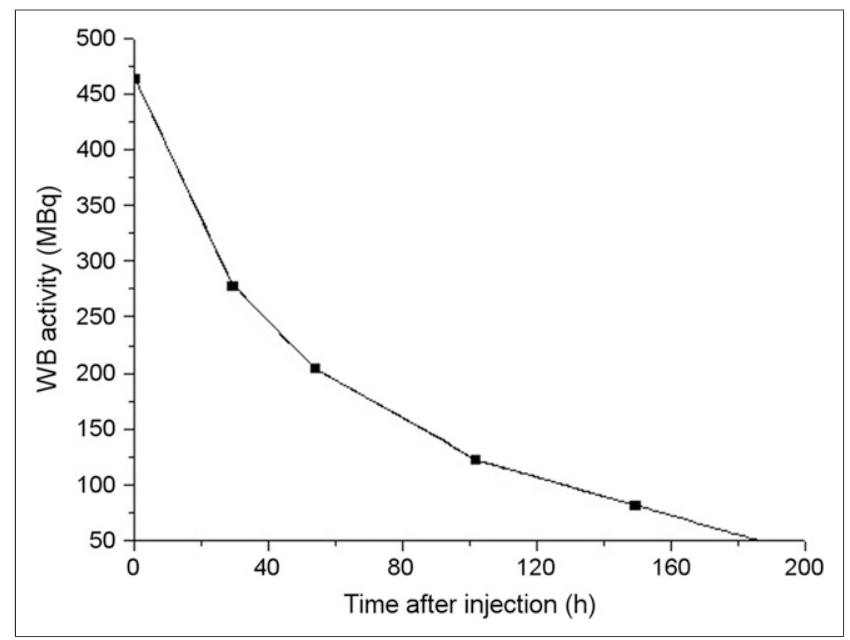

FIGURE 2. Time-activity curve of patient requiring maximum dose. WB $=$ whole body. 


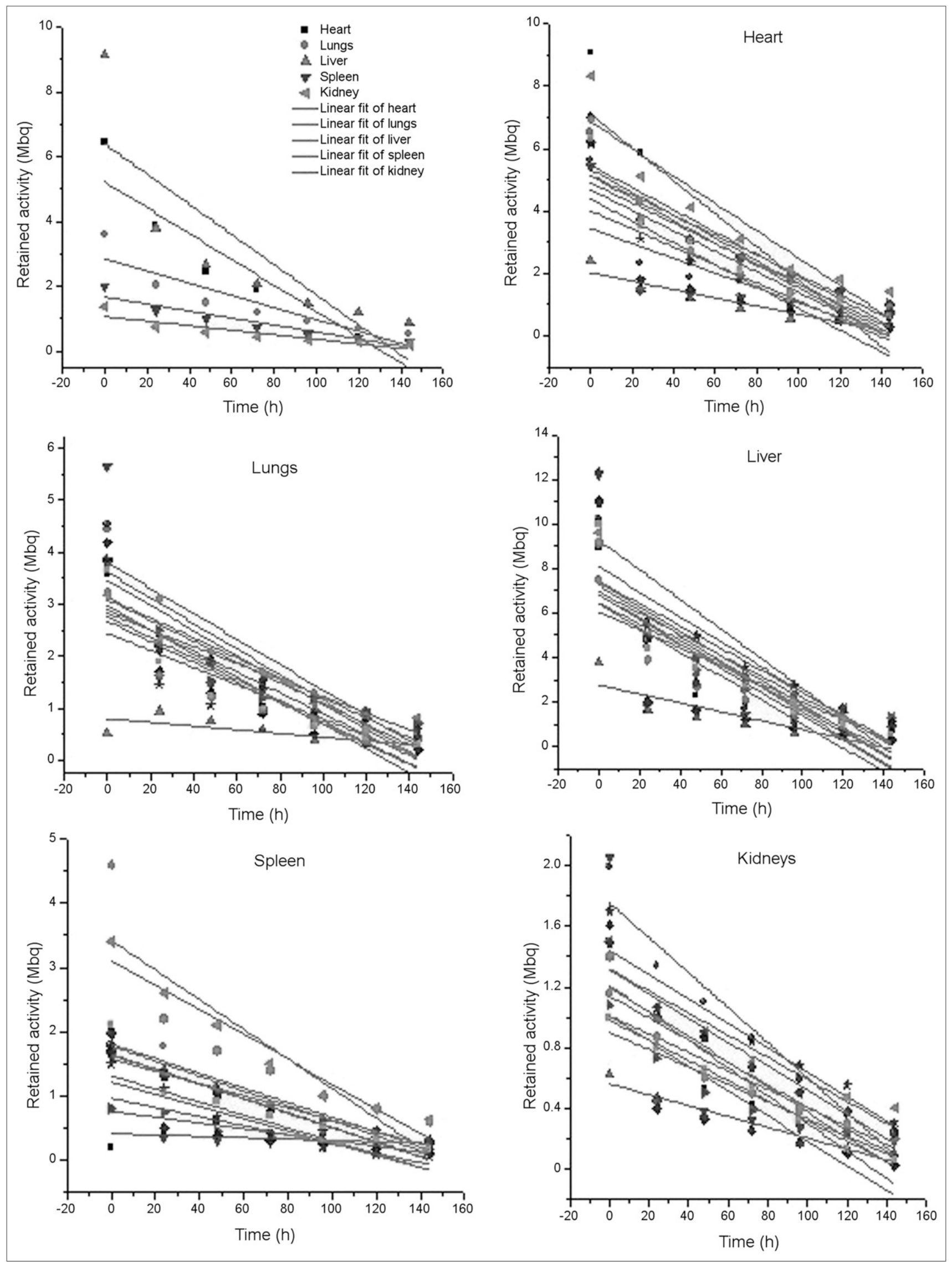

FIGURE 3. Mean and patientwise organ-specific clearance pattern from various major organs over time. 


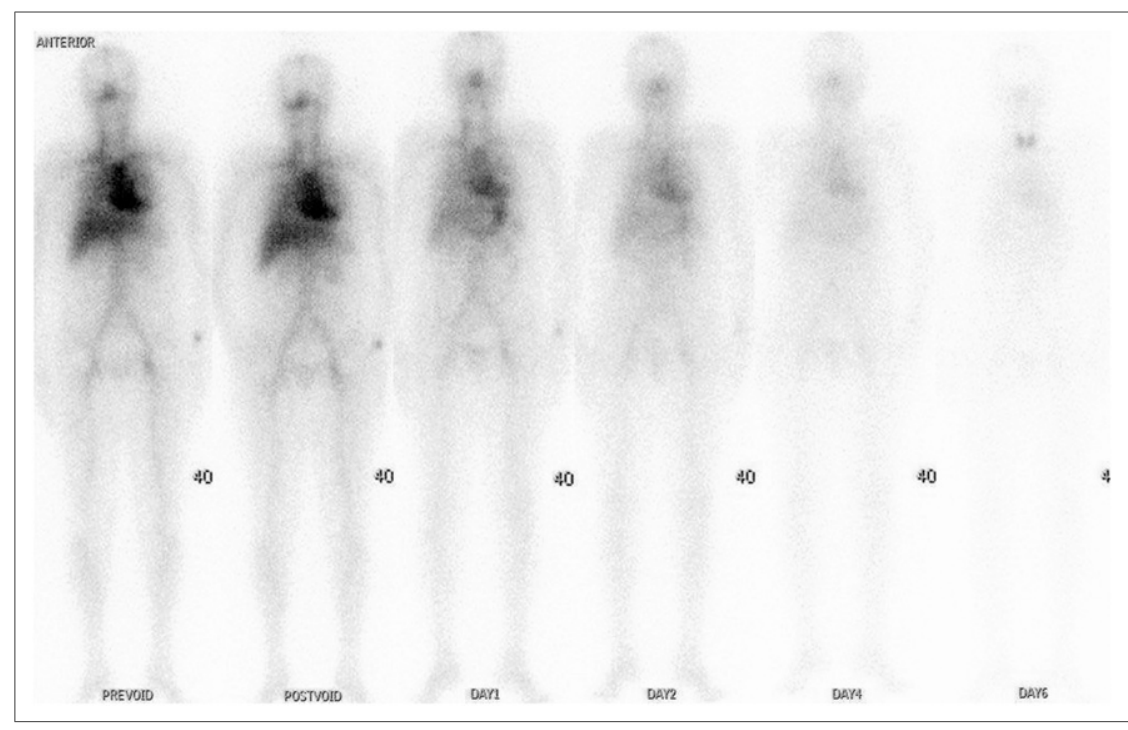

FIGURE 4. Anterior projection of serial biodistribution and clearance pattern of indigenous ${ }^{131}$ I-rituximab.

${ }^{131} \mathrm{I}$ activity injected was in the spleen (1.14 mGy/MBq), followed by the heart $(0.97 \mathrm{mGy} / \mathrm{MBq})$. In calculating the organ that received the maximum absorbed dose, we did not consider blood pool and spleen to be critical dose-limiting organs because the blood pool shows physiologic prolonged clearance and the spleen tolerates a higher absorbed dose, which may be desirable because the spleen is frequently an involved or primary site. In almost all patients, after the blood pool and spleen, the lungs $(0.25 \mathrm{mGy} / \mathrm{MBq})$ received the maximum dose per unit of injected activity, followed by the liver and kidneys $(0.18 \mathrm{mGy} / \mathrm{MBq})$. The maximum absorbed radiation dose in an individual patient was received by the spleen $(3.51 \mathrm{mGy} / \mathrm{MBq})$ of a patient who had splenic marginal zone lymphoma with spleno-

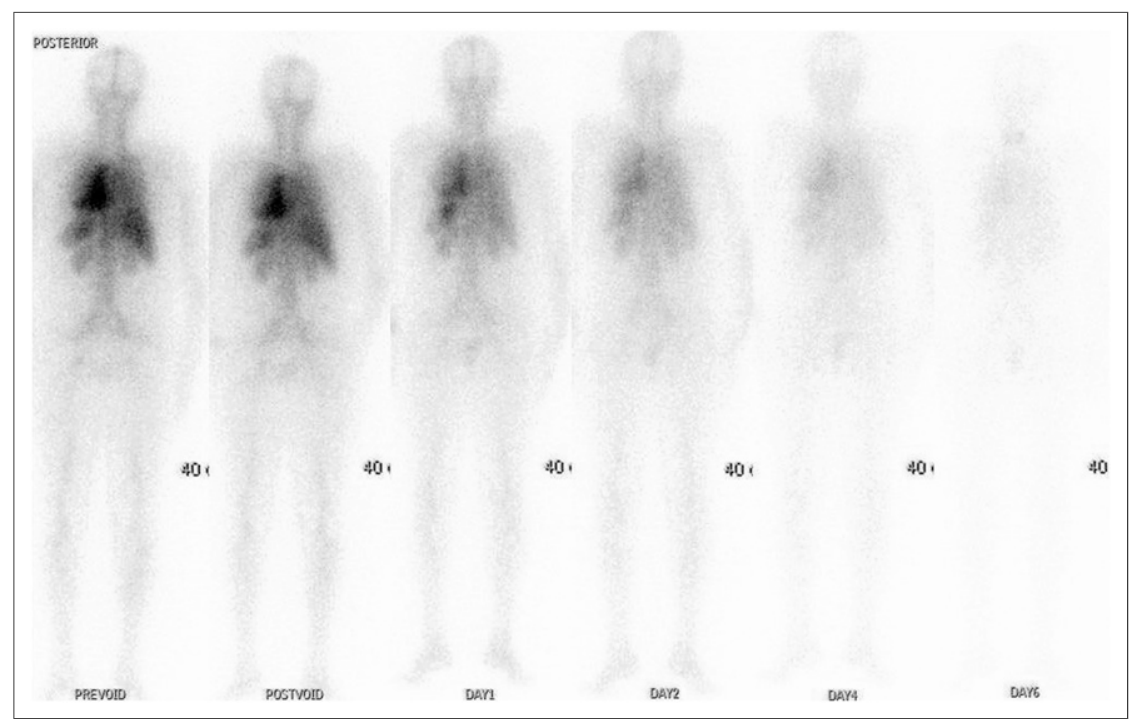

FIGURE 5. Posterior projection of serial biodistribution and clearance pattern of indigenous ${ }^{131}$ I-rituximab. megaly. The mean absorbed radiation doses to the major organs, with diagnostic and proposed therapeutic doses and mean organ residence times, are shown in Table 2. The comparative clearance fractions and therapeutic doses calculated by the cumulativeactivity method and the residencetime method are shown in Table 3 and Figure 6.

In most patients, we noticed the 2 components of clearance, fast and slow, and most such patients showed an obvious difference between the therapeutic doses calculated by the 2 methods. However, in a few such patients, for whom clearance did not show 2 distinct components, the calculated therapeutic doses were more or less comparable ( $\leq 10 \%-12 \%$ variation). A single-component clearance pattern was seen in 4 patients with minimal lesions or complete remission, whereas patients with residual tumor generally showed the 2 distinct components. The mean residence time was $69.54 \mathrm{~h}$.

\section{Patient-Specific Administered \\ Doses}

The patient-specific administered dose calculated using the cumulative-activity method ranged from $3,095.42$ to $6,330.33 \mathrm{MBq}(83.66-171.09 \mathrm{mCi})$, with a mean of $3,986.01 \pm 863.95 \mathrm{MBq}(107.73 \pm 23.35 \mathrm{mCi})$ and a median of 3,697.41 MBq (99.93 mCi).

The patient-specific administered dose calculated using the residence-time method ranged from 2,654.75 to 6,210.45 MBq (71.75-167.85 mCi), with a mean of 3,576.42 \pm 927.59 $\mathrm{MBq}(96.66 \pm 25.07 \mathrm{mCi})$ and a median of 3,421.02 MBq (92.46 mCi).

With the residence-time method, the therapeutic dose required to deliver 75 cGy was slightly less than with the cumulative-activity method. The error ranged from $0 \%$ to $22 \%$, with a mean of $10.56 \%$.

\section{DISCUSSION}

Although a combination of rituximab with established chemotherapy regimens has brought about an improvement in overall response rate, progression-free survival, and overall survival in patients with newly diagnosed B-cell NHL (21-23), the prognosis for relapsed or refractory B-cell NHL is often poor. Radioimmunotherapy has demonstrated promise not only for recurrent or refractory indolent or transformed B-cell NHL 
TABLE 2

Mean Absorbed Radiation Dose per Unit of Diagnostic and Therapeutic ${ }^{131}$ I Injected and Mean Organ Residence Time

\begin{tabular}{lccc}
\hline Organ & $\begin{array}{c}\text { Absorbed } \\
\text { diagnostic } \\
\text { dose (mGy/MBq) }\end{array}$ & $\begin{array}{c}\text { Absorbed } \\
\text { therapeutic } \\
\text { dose (Gy) }\end{array}$ & $\begin{array}{c}\text { Residence } \\
\text { time }(\mathrm{h})\end{array}$ \\
\hline Heart & 0.97 & 3.77 & 64 \\
Lungs & 0.25 & 0.97 & 62 \\
Liver & 0.18 & 0.69 & 34 \\
Spleen & 1.14 & 4.02 & 74 \\
Kidneys & 0.18 & 0.7 & 59 \\
\hline
\end{tabular}

(24) but also as first-line treatment (25) and as consolidation treatment for a first remission (26). ${ }^{131}$ I-tositumumab and ${ }^{90}$ Y-ibritumomab tiuxetan are approved for treatment of relapsed or refractory indolent or transformed B-cell NHL. ${ }^{90} \mathrm{Y}$-ibritumomab tiuxetan furthermore is approved as consolidation therapy after remission induction in previously untreated follicular lymphoma. Despite these encouraging results, the use of radioimmunotherapy remains infrequent (27).

Two advantages of indigenously labeled rituximab over commercially available rituximab can be envisaged. First, a single regimen of the commercial product can cost up to $\$ 30,000$ ( $\sim 21$ lakh Indian rupees), precluding its routine use in developing countries, whereas the indigenously labeled product is expected to cost less. Second, the antibodies used in the commercially approved radiopharmaceuticals are murine antibodies and hence may cause human antimouse antibody reactions in as many as $50 \%-60 \%$ of patients. Because rituximab, being a chimeric antibody, has a lower reported rate of human antimouse antibody reactions, retreatment can be undertaken safely.

The primary aim of this study was to determine the therapeutic dose of the indigenous ${ }^{131}$ I-rituximab and to study its biodistribution. Our study with 13 patients demonstrated that the calculated therapeutic doses were comparable to those of the commercial products. A specific feature of this study was the comparison between therapeutic doses calculated by the cumulative-activity method and therapeutic doses calculated by the residence-time method. The latter were comparable to those of the cumulative-activity method (Table 3).

Among the major critical organs, apart from the blood pool (3.77 Gy) and spleen (4.02 Gy), those with the maximum mean absorbed radiation dose at the proposed therapeutic dose were the lungs ( $0.97 \mathrm{~Gy})$, followed by the liver (0.69 Gy) and kidneys (0.7 Gy). The absorbed doses per unit of injected diagnostic radioactivity (in $\mathrm{mGy} / \mathrm{MBq}$ ) were comparable to those for the therapeutic dose and were greatest for the lungs $(0.25)$, followed by the liver and kidneys (0.18), apart from blood pool or heart (0.97) and spleen (1.14). In none of these organs was there any dose-limiting radiation exposure at the standard prescribed therapeutic doses. The maximum absorbed radiation dose received by individual organs with the administration of a therapeutic dose was well within the conventional limit of $20 \mathrm{~Gy}$. Similar to the diagnostic data, the maximum organ-specific absorbed radiation dose was received by the spleen (11 Gy) of a patient who had splenic marginal zone lymphoma with splenomegaly.

The fast and the slow components of clearance were studied and showed wide interpersonal variations. Patients with minimal lesions or complete remission showed a singlecomponent clearance pattern.

This study had limitations due mainly to the small number of patients, the variation in their stages of treatment, and the fact that the MIRD schema is based on various assumptions. Rajendran et al. demonstrated a CT volume-adjusted absorbed dose per unit of radioactivity (in $\mathrm{mGy} / \mathrm{MBq}$ ) of 1.30 for the lungs, 0.92 for the liver, 0.76 for the kidneys, 1.40 for the spleen, and 0.22 for the whole body (28). The

TABLE 3

Clearance Fractions and Therapeutic Doses Calculated by Cumulative-Activity Method and Residence-Time Method

\begin{tabular}{|c|c|c|c|c|}
\hline \multirow[b]{2}{*}{ Patient no. } & \multicolumn{2}{|c|}{ Clearance fraction } & \multicolumn{2}{|c|}{ Calculated therapeutic dose } \\
\hline & Fast component (\%) & Slow component (\%) & Cumulative-activity method (mCi) & Residence-time method (mCi) \\
\hline 1 & 23.4 & 76.6 & 83.66 & 75.66 \\
\hline $2^{*}$ & & & 93.15 & 93.2 \\
\hline 3 & 81 & 19 & 88.94 & 71.75 \\
\hline 4 & 58.5 & 41.5 & 93.42 & 92.46 \\
\hline $5^{*}$ & & & 98.42 & 93.95 \\
\hline $6^{*}$ & & & 116.6 & 108.72 \\
\hline 7 & 34.9 & 65.1 & 99.93 & 80.99 \\
\hline 8 & 22.7 & 77.3 & 100.47 & 82.68 \\
\hline $9^{*}$ & & & 99.74 & 93.89 \\
\hline 10 & 65 & 35 & 135.00 & 120.82 \\
\hline 11 & 30.9 & 69.1 & 103.66 & 83.80 \\
\hline 12 & 53.2 & 46.8 & 116.53 & 90.82 \\
\hline 13 & 79 & 21 & 171.09 & 167.85 \\
\hline
\end{tabular}




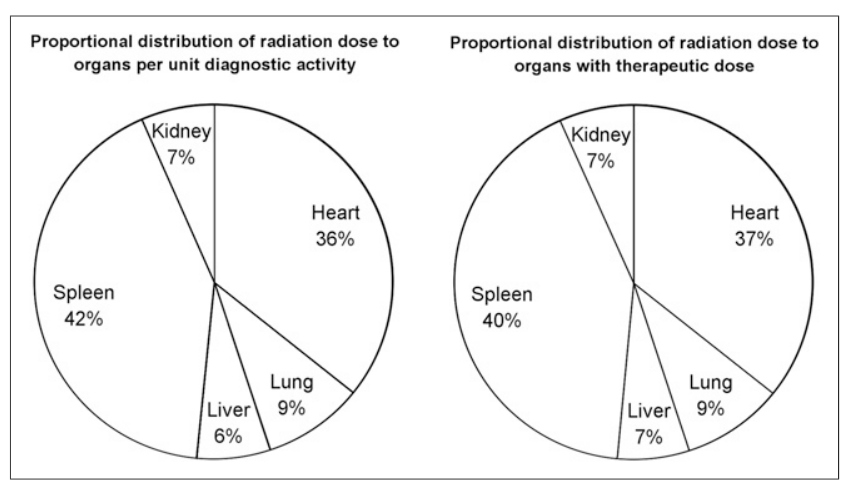

FIGURE 6. Organwise distribution of mean absorbed radiation dose per unit of diagnostic activity and with proposed therapeutic dose of radiopharmaceutical injected.

trend in the results obtained by this study resonated well with the available literature, and administration of the indigenous product for therapeutic indications was found to be safe.

At present, radioimmunotherapy is underutilized in routine practice despite approval by the responsible regulatory authorities in the United States and in Europe. Treating physicians seem hesitant to recommend radioimmunotherapy to a larger number of potentially eligible patients. This hesitation might be due to the availability of alternative nonradioactive therapies and to various logistic, educational, and economic concerns (29). Cost is certainly a limiting factor in developing countries. Data from Leahy and Turner demonstrated that radioimmunotherapy with ${ }^{131}$ I-rituximab in routine clinical outpatient practice is a safe option for relapsed or refractory indolent NHL, with half the patients achieving a durable complete response that has potential for repeat treatment (30). Recently, a possible role for radioimmunotherapy was evaluated as part of the conditioning regime before allogeneic stem cell transplantation in patients with persistent high-risk B-cell NHL. In two phase 2 trials, radioimmunotherapy proved feasible and safe in combination with a reducedintensity conditioning regime consisting of fludarabine and total-body irradiation ( $2 \mathrm{~Gy}$ ), with acceptable toxicity even in elderly and heavily pretreated patients $(31,32)$. These results provide an important basis for studying the cost effectiveness of the indigenous product in approved and future indications. The present study results add an important perspective to this particular topic.

\section{CONCLUSION}

The indigenous ${ }^{131}$ I-rituximab product has demonstrated kinetics similar to commercially available, approved radiopharmaceuticals, with the advantage of a lower human antimouse antibody response due to the pharmaceutical's being a chimeric antibody rather than murine. Considering the promising data obtained for this indigenously developed product, its use in lymphoma care for a larger patient benefit can hardly be overemphasized.

\section{DISCLOSURE}

No potential conflict of interest relevant to this article was reported.

\section{REFERENCES}

1. Longo DL. Malignancies of lymphoid cells. In: Longo DL, Fauci AS, Kasper DL, Hauser SL, Jameson JL, Loscalzo J, eds. Harrison's Principles of Internal Medicine. 18th ed. New York, NY: McGraw-Hill Education; 2012:919-935.

2. Mauch PM, Armitage JO, Diehl V, Hoppe RT, Weiss LM, eds. Hodgkin's Disease. Philadelphia, PA: Lippincott Williams and Wilkins; 1999:5.

3. SEER cancer statistics review (CSR) 1975-2014. SEER website. https://seer. cancer.gov/archive/csr/1975_2014/. Updated April 2, 2018. Accessed February $14,2019$.

4. Freedman AS, Jacobson CA, Mauch P, Aster JC. Non-Hodgkin's lymphoma. In: DeVita VT, Lawrence TS, Rosenberg SA, eds. DeVita, Hellman, and Rosenberg's Cancer: Principles and Practice of Oncology. 10th ed. Philadelphia, PA: Lippincott Williams and Wilkins; 2015:1552-1583.

5. Roschewski MJ, Wilson WH. Non-Hodgkin lymphoma. In: Niederhuber JE, Armitage JO, Doroshow JH, Kastan MB, Tepper JE, eds. Abeloff's Clinical Oncology. 5th ed. Philadelphia, PA: Elsevier; 2014:2033-2059.

6. World Cancer Report 2014 [chapter 5.13]. WHO website. https://www.who.int/ cancer/publications/WRC_2014/en/. Published 2014. Accessed February 14, 2019.

7. Marcus R, Sweetenham JW, Williams ME. Lymphoma: Pathology, Diagnosis and Treatment. 2nd ed. New York, NY: Cambridge University Press; 2013:1.

8. Sandlund JT, Onciu M. Childhood lymphoma. In: Niederhuber JE, Armitage JO, Doroshow JH, Kastan MB, Tepper JE, eds. Abeloff's Clinical Oncology. 5th ed. 2014:1873-1889.

9. Wagner JY, Schwarz K, Schreiber S, et al. Myeloablative anti-CD20 radioimmunotherapy $+/-$ high-dose chemotherapy followed by autologous stem cell support for relapsed/refractory B-cell lymphoma results in excellent long-term survival. Oncotarget. 2013;4:899-910.

10. Kaminski MS, Zasadny KR, Francis IR, et al. Radioimmunotherapy of B-cell lymphoma with [ $\left.{ }^{131} I\right]$ anti-B1 (anti-CD20) antibody. $N$ Engl J Med. 1993;329:459-465.

11. Kaminski MS, Zasadny KR, Francis IR, et al. Iodine-131 anti-B1 radioimmunotherapy for B-cell lymphoma. J Clin Oncol. 1996;14:1974-1981.

12. Press OW. Radioimmunotherapy for non-Hodgkin's lymphomas: a historical perspective. Semin Oncol. 2003;30:10-21.

13. Press OW, Rasey J. Principles of radioimmunotherapy for hematologists and oncologists. Semin Oncol. 2000;27:62-73.

14. Press OW, Shan D, Howell-Clark J, et al. Comparative metabolism and retention of iodine-125, yttrium-90, and indium-111 radioimmunoconjugates by cancer cells. Cancer Res. 1996;56:2123-2129.

15. Kameswaran M, Vimalnath K, Rajeswari A, et al. Clinical scale preparation and evaluation of ${ }^{131}$ I-rituximab for non-Hodgkin's lymphoma. Radiochim Acta. 2014; 102:553-560.

16. Turner JH, Martindale AA, Boucek J, et al. ${ }^{131} \mathrm{I}$-anti CD20 radioimmunotherapy of relapsed or refractory non-Hodgkins lymphoma: a phase II clinical trial of a non-myeloablative dose regimen of chimeric rituximab radiolabelled in a hospital. Cancer Biother Radiopharm. 2003;18:513-524.

17. Schipper MJ, Koral KF, Avram AM, Kaminski MS, Dewaraja YK. Prediction of therapy tumor-absorbed dose estimates in I-131 radioimmunotherapy using tracer data via a mixed-model fit to time activity. Cancer Biother Radiopharm. 2012;27:403-411.

18. Vose JM. Bexxar: novel radioimmunotherapy for the treatment of low-grade and transformed low-grade non-Hodgkin's lymphoma. Oncologist. 2004;9: $160-172$.

19. Wahl RL. Tositumomab and ${ }^{131}$ I therapy in non-Hodgkin's lymphoma. J Nucl Med. 2005;46(suppl):128S-140S.

20. Goldsmith SJ. Radioimmunotherapy of lymphoma: Bexxar and Zevalin. Semin Nucl Med. 2010;40:122-135.

21. Schulz H, Bohlius JF, Trelle S, et al. Immunochemotherapy with rituximab and overall survival in patients with indolent or mantle cell lymphoma: a systematic review and meta-analysis. J Natl Cancer Inst. 2007;99:706-714.

22. Pfreundschuh M, Trumper L, Osterborg A, et al. CHOP-like chemotherapy plus rituximab versus CHOP-like chemotherapy alone in young patients with good-prognosis diffuse large-B-cell lymphoma: a randomised controlled trial by the MabThera International Trial (MInT) Group. Lancet Oncol. 2006;7:379-391.

23. Habermann TM, Weller EA, Morrison VA, et al. Rituximab-CHOP versus CHOP alone or with maintenance rituximab in older patients with diffuse large B-cell lymphoma. J Clin Oncol. 2006;24:3121-3127. 
24. Emmanouilides C. Radioimmunotherapy for non-Hodgkin lymphoma: historical perspective and current status. J Clin Exp Hematop. 2007;47:43-60.

25. Kaminski MS, Tuck M, Estes J, et al. ${ }^{131}$ I-tositumomab therapy as initial treatment for follicular lymphoma. N Engl J Med. 2005;352:441-449.

26. Morschhauser F, Radford J, Van Hoof A, et al. Phase III trial of consolidation therapy with yttrium-90-ibritumomab tiuxetan compared with no additional therapy after first remission in advanced follicular lymphoma. J Clin Oncol. 2008; 26:5156-5164.

27. Illidge TM. Radioimmunotherapy of lymphoma: a treatment approach ahead of its time or past its sell-by date? J Clin Oncol. 2010;28:2944-2946.

28. Rajendran JG, Fisher DR, Gopal AK, Durack LD, Press OW, Eary JF. High-dose ${ }^{131}$ I-tositumomab (anti-CD20) radioimmunotherapy for non-Hodgkin's lymphoma: adjusting radiation absorbed dose to actual organ volumes. $\mathrm{J} \mathrm{Nucl}$ Med. 2004;45:1059-1064.
29. Schaefer NG, Huang P, Buchanan JW, Wahl RL. Radioimmunotherapy in nonHodgkin lymphoma: opinions of nuclear medicine physicians and radiation oncologists. J Nucl Med. 2011;52:830-838.

30. Leahy MF, Turner JH. Radioimmunotherapy of relapsed indolent non-Hodgkin lymphoma with ${ }^{131}$ I-rituximab in routine clinical practice: 10-year single-institution experience of 142 consecutive patients. Blood. 2011;117:45-52.

31. Bethge WA, Lange T, Meisner C, et al. Radioimmunotherapy with yttrium-90ibritumomab tiuxetan as part of a reduced intensity conditioning regimen for allogeneic hematopoietic cell transplantation in patients with advanced nonHodgkin lymphoma: results of a phase 2 study. Blood. 2010;116:1795-1802.

32. Gopal AK, Guthrie KA, Rajendran J, et al. ${ }^{90}$ Y-ibritumomab tiuxetan, fludarabine, and TBI-based nonmyeloablative allogeneic transplantation conditioning for patients with persistent high-risk B-cell lymphoma. Blood. 2011;118: 1132-1139. 